\title{
Anesthetic Management of Patients with Transoral Robotic Surgery for Obstructive Sleep Apnea Syndrome
}

\author{
Bedih Balkan'1, Mustafa Çelik², Kamil Hakan Kaya², Arzu Karaman Koç², Halil Çetingök³, \\ Gülsüm Oya Hergünsel ${ }^{1}$ \\ ${ }^{1}$ Department of Anesthesiology and Reamination, Bakirkoy Dr. Sadi Konuk Training and Research Hospital, Istanbul, Turkey \\ ${ }^{2}$ Department of Otorhinolaryngology, Head and Neck Surgery, Bakirkoy Dr. Sadi Konuk Training and Research Hospital, Istanbul, Turkey \\ ${ }^{3}$ Department of Anesthesiology and Reamination, Bagcilar Training and Research Hospital, Istanbul, Turkey
}

\begin{abstract}
Introduction: The objective of this study was to evaluate patients who underwent transoral robotic surgery (TORS) due to obstructive sleep apnea syndrome (OSAS) with regard to anesthetic management.

Methods: A total of 72 patients (20 females and 52 males) were included in this study. Their mean age was $46.94 \pm 9.02$ years (range: 27-67 years). The Epworth Sleepiness Scale, body mass index (BMI), apnea-hypopnea index, and the neck circumference were calculated for all patients included in the study. These patients were evaluated in terms of demographic information, TORS, anesthesia, peroperative findings, and complications.

Results: Evaluation of the patients with regard to ASA scores demonstrated that 14 patients (19.4\%) were detected as ASA-1, 50 patients (69.4\%) as ASA-2, and eight patients (11.2\%) as ASA-3. The mean duration of the operations was $131.93 \pm 33.67$ min (range: 64-210 min). The mean quantity of fluids used throughout the operation was 1.516.94 $\pm 226.99 \mathrm{ml}$ (range: 1.100 $2.200 \mathrm{ml}$ ). None of the patients had a history of hemorrhage requiring blood transfusion. None of the patient underwent tracheostomy. All patients were subjected to prolonged intubation and followed up in the intensive care unit for $24 \mathrm{~h}$ postoperatively. No statistically significant difference was found between the duration of surgery of the male and female patients and the amount of fluids used during surgery $(p=0.264$ and $p=0.113)$. It was demonstrated that there was no statistically significant difference between patients with $\mathrm{BMl}<$ and $>30 \mathrm{~kg} / \mathrm{m}^{2}$, during the operation $(p=0.122)$. The quantity of fluid used for patients with $\mathrm{BMI}<30 \mathrm{~kg} / \mathrm{m}^{2}$ was found to be statistically higher than of those with BMl values of $>30 \mathrm{~kg} / \mathrm{m}^{2}(p=0.006)$. Discussion and Conclusion: OSAS surgery with the TORS method under anesthesia is of utmost importance. We suggest that TORS interventions should be performed in accordance with basic endolaryngeal surgical principles of anesthesia. We are convinced that reports associated with the use of anesthesia experiences related to this subject would increase widespread use of the technique.
\end{abstract}

Keywords: Anesthesia; intubation; obstructive apnea syndrome; robotic surgery.

$\mathrm{O}$ bstructive sleep apnea syndrome (OSAS) is a complex disease characterized with partial or complete obstruction of the upper respiratory tract and oxygen desaturation during sleep ${ }^{[1-3]}$. In the literature, the term OSAS was first in- troduced in 1973 by Guilleminault et al. ${ }^{[4]}$ OSAS has a significant relationship with cardiovascular morbidity and mortality such as hypertension, heart failure, coronary heart disease, arrhythmia, sudden death, and cerebrovascular disease ${ }^{[5]}$.

Correspondence (iletişim): Mustafa Çelik, M.D. Bakirkoy Dr. Sadi Konuk Egitim ve Arastirma Hastanesi, Kulak Burun Bogaz Bas ve Boyun Cerrahisi Klinigi, Istanbul, Turkey

Phone (Telefon): +90 5335976636 E-mail (E-posta): dr.mcelik@yahoo.com

Submitted Date (Başvuru Tarihi): 13.01.2018 Accepted Date (Kabul Tarihi): 06.03.2018

Copyright 2019 Haydarpaşa Numune Medical Journal

This is an open access article under the CC BY-NC license (http://creativecommons.org/licenses/by-nc/4.0/). 
Treatment of OSAS and CPAP use is a multilevel surgical approach for appropriate patients ${ }^{[2,3]}$. Although there is no medical guide accepted by everyone in the literature about which surgical approach to apply in cases with OSAS, the main success in OSAS surgery is to determine the correct level of collapse and to apply the appropriate surgical approach [6]. Although obstruction can be seen at different levels in OSAS patients, transoral robotic surgery (TORS) has been one of the successful techniques currently applied for obstruction, especially at the tongue base and epiglottis level [7-10].

TORS is a very new technology and technique that allows minimally invasive surgery in head and neck surgery [7-11]. TORS was described by Weinstein and O'Malley et al. [11] in 2005 who described radical tonsillectomy, supraglottic laryngectomy, and resection tongue base using transoral approach. Later on, chordectomy, nasopharyngeal, and oropharyngeal approaches realized using TORS have been reported with TORS. FDA approved the use of TORS in benign and malign lesions of oral cavity, oropharynx, pharynx, and larynx in adults in $2010^{[12] .}$

Robotic surgery provides advantages for patients such as better hemostasis, lesser amount of bleeding and pain, shortened hospitalization, lesser morbidity, and faster return to normal oral feeding ${ }^{[8-11]}$.

Experience of the anesthesia team and its collaboration with the robotic surgical team is very important for the safe application of TORS. Moreover, endolaryngeal surgery is an absolute must to proceed with TORS. Since pharynx collapses during sleep and anesthesia in patients with OSAS, it is difficult to provide airway patency under tracheal intubation and anesthesia.

In TORS practice, anesthesiologists should be alert and prepared for every situation. It is applied in very few clinics in our country yet, so the presence of experienced anesthesia team makes safe and effective TORS application mandatory. In this study, our basic anesthesia approaches and experiences in cases with OSAS managed with TORS performed by our otolaryngology clinic were presented The main points of management of TORS anesthesia were reviewed.

\section{Materials and Methods}

This retrospective clinical study included 72 patients (20 female, 52 male, mean age $46.94 \pm 9.02$ years, range $27-67$ years) who were operated using TORS for obstructive sleep apnea between June 2012 and June 2017 in our hospital. The study was approved by the Ethics Committee of the same hospital (Ethics board decision no. 2017/113). The study was conducted in accordance with the Helsinki Decla- ration of Principles and Guidelines for Good Clinical Practice. The demographic information of the cases included in the study was obtained by screening the files in the hospital registry system. Epworth Sleepiness Scale (ESS) scores, body mass index (BMI), apnea-hypopnea index (AHI), and neck circumference were calculated for the subjects included in the study.

The parameters such as operative data and its characteristics, intraoperative bleeding, development of laryngeal edema, post-operative pain, morbidities, and tracheotomy requirement of the cases with OSAS who underwent TORS in the operating room of our hospital performed with Vinci Surgical Systems (Intuitive Surgical Inc., Sunnyvale, California) were retrospectively reviewed.

The patients who would undergo TORS were brought into the operating room, and electrocardiography, non-invasive arterial pressure, and peripheral oxygen saturation monitoring were performed in the operating room. Anesthesia was induced with 2-3 mg midazolam (Dormicum ${ }^{\oplus}$ ), 1-2 $\mathrm{mcg} / \mathrm{kg}$ fentanyl, and $2 \mathrm{mg} / \mathrm{kg}$ propofol (in cardiac risk patients: 2-4 mg midazolam and + 2-4 mcg/kg fentanyl) infused through 18-20 G IV cannulas inserted into the back of the both hands of the patient.

Muscle relaxation was achieved with $0.8-1 \mathrm{mg} / \mathrm{kg}$ midazolam (CURON 50MG $/ 5 \mathrm{ML}^{\circledR}$ ) after observing that mask ventilation was sufficient. A 6.5-7.5 nasal tube (Laser Shield II; Medtronic Xomed, Inc., Jacksonville, FL, USA) was intubated with the help of a video laryngoscope. Since monopolar cautery or laser was used to cut the tissue or control the bleeding during operation, intubation was done with a laser protected 5.0-6.0 Fr tube. Nasotracheal intubation was performed for all cases. All cases were treated with antibiotic prophylaxis with a cephalosporin ( $1 \mathrm{~g}$ iv lespor ${ }^{\circledR}$ ). Crystalloid infusion was initiated in all cases at a dose of $7 \mathrm{ml} / \mathrm{kg} / \mathrm{h}$. Arterial catheterization was performed for the monitorization of four invasive arterial pressures in cases in the ASA III risk category. All cases were taken into supine position. Priorly, Da Vinci robotic system (Intuitive Surgical, Sunnyvale, CA, USA) was installed.

After installation, the robot was brought closer to the operation table. Throughout the operation, all cases were protected with protective goggles and protective tooth mold. The Feyh-Kastenbauer ${ }^{\circledast}$ (F-K) retractor (Gyrus Medical, Tuttlingen, Germany) was used for oral and laryngeal exposure. Surgical resection area was reached with three robotic arms from the mouth opening to the upper airway of the cases. On the one arm of the robot, a 00 endoscope of 8 $\mathrm{mm}$ in caliber, a $5 \mathrm{~mm}$-thick monopolar cautery, or laser ap- 
plicator was mounted on the second arm of the robot. On the third arm of the robot, aMaryland ${ }^{\circledR}$ dissector of $5 \mathrm{~mm}$ in diameter or a Schertel Grasper ${ }^{\circledast}$ was placed. Monopolar cautery and laser were used for tissue cutting and dissection. Schertel Grasper ${ }^{\circledR}$ and Maryland Disector ${ }^{\circledR}$ were used to grasp and dissect the tissue.

Monopolar cautery, hemoclips, and Thulium ${ }^{\circledast}$ laser were used for hemostasis. Hypotensive anesthesia was achieved with iv remifentanil during the operation. $\mathrm{FiO}^{2}$ was reduced to $30 \%$ to prevent potential burns that could happen due to laser or monopolar cauterization. To prevent peroperative and postoperative bronchospasm, methylprednisolone (PREDNOL ${ }^{\oplus}$ ) $3 \mathrm{mg} / \mathrm{kg}$ iv and ranitidine (ULCURAN ${ }^{\circledR}$ ) 1 ampoule iv were administered for the laryngeal edema prophylaxis at doses of $3 \mathrm{mg} / \mathrm{kg}$ iv of theophylline (TEOBEG ${ }^{\circledR}$ ) iv. Meperidine (ALDOLAN ${ }^{\circledR}$ ) $0.5 \mathrm{mg} / \mathrm{kg}$ iv was administered 30 min before the end of the operation for post-operative analgesia.

\section{Statistical Analyses}

Number Cruncher Statistical System, 2007 (Kaysville, Utah, USA) program was used for statistical analysis. Mean, standard deviation, median, lowest, highest, frequency, and ratio values were used in the descriptive statistics of the data. The distribution of variables was measured by Kolmogorov-Smirnov test.

Mann-Whitney U-test was used in the analysis of quantitative independent data. Chi-square test was used to analyze qualitative independent data, and Fisher's test was used when conditions for Chi-square test were not met. Dunn's Multiple Comparison test with Bonferroni correction was used in multiple comparisons between groups. KruskalWallis $\mathrm{H}$-test was used for non-parametric one-way ANOVA. Statistical significance was evaluated at $p<0.05$ level.

\section{Results}

The mean values for $\mathrm{AHI}$ (35.62 \pm 17.34 : Range 14-94.6), BMI

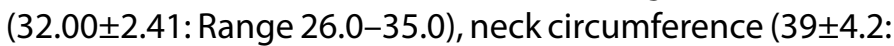
Range $30 \mathrm{~cm}-46 \mathrm{~cm}$ ), and ESS (9.6 \pm 6.6 : Range, 0-24) were as indicated in parentheses. The demographic characteristics of the cases are given in Table 1. The types of surgery performed in the cases are summarized in Table 2.

ASA scores of the cases were evaluated, and 14 (19.4\%) cases were evaluated in ASA-1, 50 cases (69.4\%) in ASA-2, and 8 cases (11.2\%) in the ASA-3 categories. The mean duration of operation was $131.93 \pm 33.67 \mathrm{~min}$ (range $64-210$ min). The average amount of fluid used during the operation was $1.516 .94 \pm 226.99 \mathrm{ml}$ (range $1.100-2.200 \mathrm{ml}$ ). None of the cases had bleeding requiring blood transfusion.

Tracheotomy was not opened in any case. All cases were treated with nasal intubation for $24 \mathrm{~h}$ postoperatively in the intensive care unit. Sedation was achieved with remifentanil (ULTIVA $\left.{ }^{\oplus}\right)(0.1-0.5 \mathrm{mcg} / \mathrm{kg} / \mathrm{h})$ and dexmedetomidine $(0.2-0.4 / \mathrm{kg} / \mathrm{h})$ combination according to the patient's hemodynamic status.

Bispectral index (BIS) monitoring allows us to follow up the depth of sedation and awake EEG signals numerically. BIS index was kept between 60 and 70 . All the cases with stable vital findings were extubated the other day and taken into service without any problems. In these cases, oral feeding started on day 3. Any episode of nausea or vomiting which required an antiemetic treatment did not occur in the recovery room. Narcotic analgesics were not required for any patient transferred to the service during post-operative period. After the cases were transferred to the service, none of the cases had bleeding requiring blood transfusion. No post-operative infection was not observed in any of the cases.

There was no statistically significant difference between the amounts of fluid used during surgery and operative times of male and female cases ( $p=0.264, p=0.113$ ) (Table 3 ).

There was no statistically significant difference between the cases with BMls below and above $30 \mathrm{~kg} / \mathrm{m}^{2}$ as for operative times $(p=0.122)$. It was found that the amount of fluid used was statistically higher in cases with a BMI $>30 \mathrm{~kg} / \mathrm{m}^{2}$

Table 1. Demographic characteristics of the cases

\begin{tabular}{lc}
\hline Characteristics & Mean \\
\hline Age (year) & $46.94 \pm 9.02$ \\
(range: $27-67)$ \\
Male patients, $\mathrm{n}(\%)$ & $52(72.2)$ \\
Female patients, $\mathrm{n}(\%)$ & $20(27.8)$ \\
Neck circumference, cm $\pm \mathrm{SD}$ & $39.0 \pm 4.2$ \\
Epworth sleep score, i $\pm \mathrm{SS}$ & $9.6 \pm 6.6$ \\
Mallampati score 3-4 (\%) & $63(87.5)$ \\
AHI/h \pm SD & $35.62 \pm 17.34$
\end{tabular}

AHI: Apnea-Hypopnea Index; SD: Standard deviation.

Table 2. Distribution of surgeries among cases

\begin{tabular}{lc}
\hline $\begin{array}{l}\text { Cases } \\
\text { Type of the surgery performed }\end{array}$ & $\mathbf{n}(\%)$ \\
\hline TBR & $3(4.17)$ \\
TBR + EP + UP + APP & $12(16.67)$ \\
TBR + EP & $10(13.89)$ \\
EP + UP + APP & $1(1.39)$ \\
TBR + EP + UP + APP + tonsillectomy & $43(59.72)$ \\
TBR + UP + APP + tonsillectomy & $3(4.17)$ \\
Total & $72(100)$ \\
\hline
\end{tabular}

TBR: Resection of the tongue base; EP: Epiglottoplasty; UP: Uvuloplasty; APP: Anterior palatoplasty. 
when compared with BMls $<30 \mathrm{~kg} / \mathrm{m}^{2}$ ( $\mathrm{p}=0.006$ ) (Table 4). There was no significant difference between the operative times of the patients with mild (AHI: $5-15 / \mathrm{h}$ ), moderate (AHI: $15-30 / h)$, and severe $(>30 / h)$ OSAS $(p=0.132)$. The $\mathrm{AHI}$ index was found to be higher in patients with moderate $(15-30 / h)$ than in those with severe OSAS $(p=0.029)$ (Table 5). There was no statistically significant difference as for intraoperative amount of fluid used between patients with mild and moderate OSAS $(p=1.00)$. There was no statistically significant difference between the amount of fluid used in operation of the patients with mild and severe OSAS in terms of AHIs ( $p=0.438)$ (Table 6$)$.

Table 3. Distribution of operative times and the amount of fluid used between male and female patients

\begin{tabular}{lccc}
\hline & \multicolumn{3}{c}{ Gender } \\
\cline { 2 - 4 } & Female & Male & $\mathbf{P}^{*}$ \\
\hline Operative time (min) & $139.27 \pm 35.20$ & $130.00 \pm 33.31$ & 0.264 \\
The amount of fluid & $1.620 .00 \pm 239.64$ & $1.489 .82 \pm 217.65$ & 0.113 \\
used (ml) & & & \\
\hline
\end{tabular}

*Mann-Whitney U-test.

Table 4. Distribution of operative times, and the amount of fluid used according to body mass indices

\begin{tabular}{lccc}
\hline & \multicolumn{3}{c}{ BMI } \\
\cline { 2 - 4 } & $<\mathbf{3 0 ~} \mathbf{~ g g / \mathbf { m } ^ { 2 }}$ & $>\mathbf{3 0} \mathbf{~ k g} / \mathbf{m}^{\mathbf{2}}$ & $\mathbf{P *}$ \\
\hline Operative time (min) & $143.85 \pm 30.42$ & $129.31 \pm 34.02$ & 0.122 \\
The amount of fluid & $1.652 .31 \pm 173.31$ & $1.487 .12 \pm 227.69$ & 0.006 \\
used (ml) & & & \\
\hline
\end{tabular}

*Mann-Whitney U-test; BMI: Body mass index.

Table 5. Distribution of operative times and the amount of fluid used according to apnea-hypopnea indices

\begin{tabular}{lcc}
\hline AHI & $\begin{array}{c}\text { Operative } \\
\text { time (min) }\end{array}$ & $\begin{array}{c}\text { Amount of } \\
\text { fluid used }(\mathbf{m l})\end{array}$ \\
\hline Mild (AHI: $5-15 / \mathrm{h})$ & $135.00 \pm 28.06$ & $1.600 .00 \pm 70.71$ \\
Moderate $(\mathrm{AHI}: 15-30 / \mathrm{h})$ & $143.61 \pm 30.33$ & $1.626 .67 \pm 217.36$ \\
Severe (AHI: $>30 / \mathrm{h})$ & $127.33 \pm 34.81$ & $1.468 .16 \pm 226.71$ \\
$\mathrm{P}^{*}$ & 0.132 & 0.020 \\
\hline
\end{tabular}

*Kruskal-Wallis H-test; AHI: Apnea-hypopnea index.

Table 6. Multiple comparisons of the amount of fluid used according to apnea-hypopnea indices

\begin{tabular}{lc}
\hline Apnea-hypopnea groups & $\mathbf{P}^{*}$ \\
\hline Mild-moderate & 1.00 \\
Mild-severe & 0.438 \\
Moderate-severe & 0.029 \\
\hline
\end{tabular}

*Dunn's multiple comparison test with Bonferroni correction.

\section{Discussion}

With the widespread use of robotic surgery, management of anesthesia for the cases undergoing robotic surgery has also become important. The goal of the robotic surgery is to provide appropriate surgical treatment using minimally invasive techniques and with minimal complications $[7,8]$.

TORS and OSAS surgery are a new surgical method that is newly applied in the world. In cases with OSAS, pathologies at the levels of tongue root and epiglottis are treated with TORS. Since access to these regions with ample blood perfusion is difficult, the surgical procedures have lower success but have relatively higher complication rates. In the literature, previously laser epiglottectomy, laser partial epiglottectomy, and diathermy epiglottectomy have been described for the treatment of OSAS. In these transoral endoscopy-assisted techniques described, $<30 \%$ of the results were successful, with higher risk of complications ranging between $5 \%$ and $25 \%$, and in open techniques, need for tracheotomy, related morbidity, and technical difficulties have led to search for new technical modalities [13, 14].

OSAS surgery using TORS was firstly reported by Vicini et al. [7] in 2011. Later on, surgical case series of OSAS managed with TORS have been reported, and then TORS gained importance as a safe surgical technique for pathologies at the level of, especially, root of the tongue and epiglottis. In our country, Kayhan et al. ${ }^{[15]}$ reported TORS as a safe, efficient, and effective method for the surgical treatment of OSAS. With TORS, it is possible to interfere with pathologic collapses in upper respiratory tracts except nasopharynx. Da Vinci robotic surgical platform provides superior 3-D HD vision. In addition, surgical advantages such as tremor filtration with 5-mm instruments which can mimic the wrist on seven planes, leaving instruments in the surgical field, using both hands simultaneously, ability to intervene to, and suturing of the surgical field with two different instruments allow performance of more skillful surgery compared to endoscopic surgery ${ }^{[11,13]}$.

In the series of OSAS managed with TORS, every surgeon appears to display a different surgical approach. Vicini et al. [10] reported that they priorly ensured the airway patency by performing tracheotomy before proceeding further with TORS in cases with OSAS. In their series, Friedman et al. [14] reported that they did not open tracheotomy, beforehand. In their series, Toh et al. ${ }^{[9]}$ and Lin et al. ${ }^{[8]}$ reported that they performed robotic surgery without opening tracheotomy. In this study, tracheotomy was not performed in cases with OSAS treated using TORS. After the cases had nasotracheal intubation, the patients underwent robotic 
surgery after the nasotracheal tubes were inserted and the cases were not immediately extubated and followed up for $24 \mathrm{~h}$ with extended intubation in the post-operative intensive care unit.

Patients with OSAS that underwent TORS are challenging and risky cases in terms of intubation. Even if the operation is initiated before the tracheotomy is planned, emergency tracheotomy should be prepared for cases with insufficient exposures or those developed collapses.

The major disadvantage of TORS is that the mouth opening is narrow for robotic endoscopes and instruments. For this reason, we prefer nasal intubation to manipulate instruments easily. With nasal intubation, intubation tube is removed away from surgical field. In addition, as described by other authors, there is no need to suture the skin or other tissue to fix the intubation tube [11].

TORS should be practiced in accordance with the principles of endolaryngeal surgery. In TORS, monopolar cautery or laser is used. For this reason, the intubation tube must be resistant to the effects of laser and heat. In addition, during anesthesia, TORS should be performed under low oxygen saturation. In this study, nasotracheal intubation was applied to all cases, and cases were prepared in accordance with the principles of endolaryngeal surgery.

To be able to apply TORS for cases with OSAS, it is necessary to retract the mouth open for at least $2 \mathrm{~cm}{ }^{[15,16]}$. It should be predicted that difficulties may be experienced in pharyngeal and laryngeal exposures in cases with inadequate mouth opening and in those with a history of difficult intubation. In TORS, F-K retractor is used for exposure. Experience is required for its placement in the mouth and for its convenient use. Good muscle relaxation should be achieved for comfortable placement of the F-K retractor. Muscle laxity must be well maintained throughout the operation. If this is not achieved well, then complaints such as jaw joint problem, trismus, and neck pain may be seen during the post-operative period. In addition, the patients should be warned that placement of FK retractors may cause tooth loss.

The intraoperative complications and the amount of bleeding in cases with OSAS during TORS have been reported to be lower than those of open surgery. In their published series, Vicini et al. ${ }^{[16]}$ reported intraoperative bleeding in only $0.4 \%$ of their cases. In this study, bleeding was not observed at a level that would require blood transfusion. The amount of bleeding seen in all cases was $<20 \mathrm{cc}$. However, the anesthesia team should be prepared for possible bleeding episodes and should have appropriate blood supply at hand. It should not be forgotten that greater amount of blood transfusions may be needed in cases where it is necessary to switch to open surgery due to excessive bleeding. One of the most important advantages of TORS as a surgical treatment of OSAS is its shorter operative time. While initially reported series had long operative times, Vicini et al. ${ }^{[10]}$ reported that, as experience increased, the duration of operation was shortened. In this study, it was observed that the operative time was prolonged due to the long period of robot installation, especially in the first cases, and as the experience increased, the operative time decreased.

It was observed that the amount of anesthetic agents applied was also lower with the shortening of the operative time. There was no significant relationship between AHI scores and operative times. No significant difference was found between the AHI scores and the amount of fluid delivered.

In TORS applied for cases with OSAS, anesthesia, and perioperative care, as in the case with other head and neck surgeries, involve intraoperative monitorization, prophylactic measures, observation of the effects of laser, and cauterization, post-operative close follow-up, and analgesia.

The preferred method of anesthesia is general anesthesia with nasotracheal intubation as in other upper airway interventions ${ }^{[17]}$. Nasotracheal intubation provides airway safety and controlled respiration against aspiration. Muscle relaxation using vecuronium or rocuronium is necessary to facilitate surgery $[17,18]$.

As in the open surgical approach, inhalation anesthesia, TIVA is preferred in the maintenance of anesthesia during TORS performed for cases with OSAS. Desflurane is more frequently preferred due to its fast-onset and rapid recovery properties, especially due to low blood-gas and tissueto-blood solubility. Desflurane provides easy control of the depth of anesthesia without affecting the cardiac output. Airway irritation is its disadvantage ${ }^{[17]}$. We also preferred desflurane and sevoflurane due to their rapid recovery properties. Sevoflurane is preferred for cases with respiratory problems due to its bronchodilatory and non-irritating properties.

In cases where TORS is applied, intubation tube and airway burn may develop secondary to the application of monopolar cautery or laser. To prevent this complication, intubation should be done using an aluminum-coated laser-protected tube, and the perioperative $\mathrm{FiO}^{2}$ should be reduced to $30 \%{ }^{[19]}$. Care should be taken in terms of the development of post-operative laryngeal edema and extubation should be planned well. In this study, airway burns were not observed in any case. 


\section{Conclusion}

Anesthesia management in TORS performed for cases with OSAS is very important. With this evaluation, which is one of the first robotic ENT series in our country, we believe that airway safety can be achieved by paying attention to postoperative extubation timing in case of laryngeal edema, especially in compliance with basic anesthetic principles of endolaryngeal surgery in transoral robotic interventions. We are convinced that reporting anesthesia experiences related to this subject will promote widespread use of this technique.

Ethics Committee Approval: The study was approved by the Ethics Committee of the same hospital (Ethics board decision no. 2017/113). The study was conducted in accordance with the Helsinki Declaration of Principles and Guidelines for Good Clinical Practice.

Peer-review: Externally peer-reviewed.

Authorship Contributions: Concept: B.B., M.Ç., K.H.K., A.K.K., H.Ç., G.O.H.; Design: B.B., M.Ç., K.H.K., A.K.K., H.Ç., G.O.H.; Data Collection or Processing: B.B., M.Ç., K.H.K., A.K.K., H.Ç., G.O.H.; Analysis or Interpretation: B.B., M.Ç.; Literature Search: B.B., M.Ç.; Writing: M.Ç.

Conflict of Interest: None declared.

Financial Disclosure: The authors declared that this study received no financial support.

\section{References}

1. Altintaş A, Yegin Y, Çelik M, Kaya KH, Koç AK, Kayhan FT. Interobserver Consistency of Drug-Induced Sleep Endoscopy in Diagnosing Obstructive Sleep Apnea Using a VOTE Classification System. J Craniofac Surg 2018;29:e140-3.

2. Gregório MG, Jacomelli M, Figueiredo AC, Cahali MB, Pedreira WL Jr, Lorenzi Filho G. Evaluation of airway obstruction by nasopharyngoscopy: comparison of the Müller maneuver versus induced sleep. Braz J Otorhinolaryngol 2007;73:618-22.

3. Qureshi A, Ballard DR. Obstructive Sleep Apnea. J Allergy Immunol 2003;112:643-51. [CrossRef]

4. Guilleminault C, Hill MW, Simmons FB, Dement WC. Obstructive sleep apnea: electromyographic and fiberoptic studies. Exp Neurol 1978;62:48-67. [CrossRef]

5. Lee CH, Kim DK, Kim SY, Rhee CS, Won TB. Changes in Site of Obstruction in Obstructive Sleep Apnea Patients According to Sleep Position: A DISE Study. Laryngoscope 2015;125:248-54.

6. Yegin Y, Çelik M, Kaya KH, Koç AK, Kayhan FT. Comparison of drug-induced sleep endoscopy and Müller's maneuver in diagnosing obstructive sleep apnea using the VOTE classifica- tion system. Braz J Otorhinolaryngol 2017;83:445-50.

7. Vicini C, Montevecchi F, Dallan I, Canzi P, Tenti G. Transoral robotic geniohyoidpexy as an additional step of transoral robotic tongue base reduction and supraglottoplasty: feasibility in a cadaver model. ORL J Otorhinolaryngol Relat Spec 2011;73:147-50. [CrossRef]

8. Lin HC, Friedman M, Chang HW, Gurpinar B. The efficacy of multilevel surgery of the upper airway in adults with obstructive sleep apnea/hypopnea syndrome. Laryngoscope 2008;118:902-8. [CrossRef]

9. Toh ST, Han HJ, Tay HN, Kiong KL. Transoral robotic surgery for obstructive sleep apnea in Asian patients: a Singapore sleep centre experience. JAMA Otolaryngol Head Neck Surg 2014;140:624-9. [CrossRef]

10. Vicini C, Montevecchi F, Tenti G, Canzi P, Dallan I, Huntley TC. Transoral robotic surgery: Tongue base reduction and supraglottoplasty for obstructive sleep apnea. Operative Tecniques in Otolaryngology 2012;23:45-7. [CrossRef]

11. Weinstein GS, O'malley BW Jr, Hockstein NG. Transoral robotic surgery: supraglottic laryngectomy in a canine model. Laryngoscope 2005;115:1315-9. [CrossRef]

12. University of Pennsylvania School of Medicine. FDA clears TransOral robotic surgery. Science Daily. Jan 6, 2010. Available at: http://www.sciencedaily.com /releases/2010/01/100104114553.htm. Accessed Oct 7, 2010.

13. Friedman M, Ibrahim H, Bass L. Clinical staging for sleep-disordered breathing. Otolaryngol Head Neck Surg 2002;127:13-21.

14. Friedman M, Hamilton C, Samuelson CG, Kelley K, Taylor D, Pearson-Chauhan $\mathrm{K}$, et al. Transoral robotic glossectomy for the treatment of obstructive sleep apnea-hypopnea syndrome. Otolaryngol Head Neck Surg 2012;146:854-62.

15. Kayhan FT, Kaya KH, Koç AK, Yegin Y, Yazici ZM, Türkeli S, et al. Multilevel Combined Surgery With Transoral Robotic Surgery for Obstructive Sleep Apnea Syndrome. J Craniofac Surg 2016;27:1044-8. [CrossRef]

16. Vicini C, Montevecchi F, Campanini A, Dallan I, Hoff PT, Spector $\mathrm{ME}$, et al. Clinical outcomes and complications associated with TORS for OSAHS: a benchmark for evaluating an emerging surgical technology in a targeted application for benign disease. ORL J Otorhinolaryngol Relat Spec 2014;76:63-9.

17. Chi JJ, Mandel JE, Weinstein GS, O'Malley BW Jr, et al. Anesthetic considerations for transoral robotic surgery. Anesthesiol Clin 2010;28:411-22. [CrossRef]

18. Hockstein NG, O'Malley BW Jr, Weinstein GS. Assessment of intraoperative safety in transoral robotic surgery. Laryngoscope 2006;116:165-8. [CrossRef]

19. Wang HM, Lee KW, Tsai CJ, Lu IC, Kuo WR, et al. Tracheostomy tube ignition during microlaryngeal surgery using diode laser: a case report. Kaohsiung J Med Sci 2006:199-202. 